\title{
Commercialization of Superconductors Spurs International Competition
}

\section{U.S. Consensus Remains Elusive}

In these days of budget deficits and trade imbalances, "high-technology competitiveness" is an oft-heard phrase. There is already fear in Washington that the Japanese will be the first to commercialize the new ceramic oxide compounds that remain superconducting at temperatures up to almost $100 \mathrm{~K}$. On June 10, the House Committee on Science, Space, and Technology held hearings to look into the possible need for a federally coordinated national superconductor R\&D effort, but did not find much support for one.

The Japanese have had several wellknown programs in diverse high-tech areas such as very large scale integrated circuits, optoelectronics, and advanced computers, mainly under the sponsorship of the Ministry of International Trade and Industry (MITI). But Shinroku Saito, president of the Technological University of Nagaoka, in answer to a question, testified that a MITI-coordinated program in superconductivity is not an immediate prospect. And H. Kent Bowen of the Massachusetts Institute of Technology, just back from a trip to Japan, reported that Japanese industry is divided on the need for one.

Nonetheless, considerable anxiety in the United States traces to the early formation in Japan of two committees. One committee under the auspices of the Science and Technology Agency and headed by Saito is called the New Superconducting Materials Forum. The forum, which has more than 100 industrial members, is actually open to foreign participation. The second committee, the Forum for Industrial Development of Superconductor Technology, is a more exclusive MITI-sponsored group with only 20 members.

Partly in retaliation, early this spring, Senator Dave Durenburger (R-Minnesota) and Representative Don Ritter ( $R$ Pennsylvania) introduced identical bills calling for the establishment of a national commission on superconductors. The commission's charter would be to recommend ways to speed up the development of superconductors for use in commercial and defense applications. Relaxation of antitrust rules to allow companies to do research in a cooperative mode is one of the ways the commission is to look into this.

On June 9, Senator Pete Domenici (DNew Mexico) announced his intention to introduce legislation promoting an enhanced role for the U.S. national laboratories in several areas of science and technology, including new superconducting materials. In the latter area, for example, Domenici would have the Department of Energy establish cooperative governmentindustry-university research centers at the national laboratories.

While sentiment for a coordinated national superconductivity program may be high in some parts of Congress, the fervor does not seem widespread. Late in July, for example, the Office of Science and Technology Policy and several federal agencies cosponsored a "Federal Conference on Commercial Applications of Superconductivity" in Washington, DC. The conference's goal was to get industry researchers together with those from government and academe in a more informal way to work out their own connections.

Similarly, Praveen Chaudhari, vice president of science of the IBM Research Division, testified he would welcome increased federal support for basic research in superconductivity but that the company would prefer to find its own path into the commercial world. And Linden Blue, vice chairman of GA Technologies, acknow!edged that his company would take a dim view of any venture that comprised proprietary interests.

In the meantime, Erich Bloch, director of the National Science Foundation told the committee that federal support for basic research on the new superconductors totals some $\$ 30$ million during the current fiscal year, with some additional money going toward applications. Other agency officials outlined plans for increased spending in fiscal 1988. But, despite some enthusiasm for enlarging the role of the national laboratories, the overall sentiment among those testifying at the hearings seemed to be that the usual American way of doing research and converting its fruits into products is the best.

ARTHUR L. ROBINSON

Editor's Note: The article on page 50 reports on the July Federal Conference on Commercial Applications of Superconductivity mentioned above.

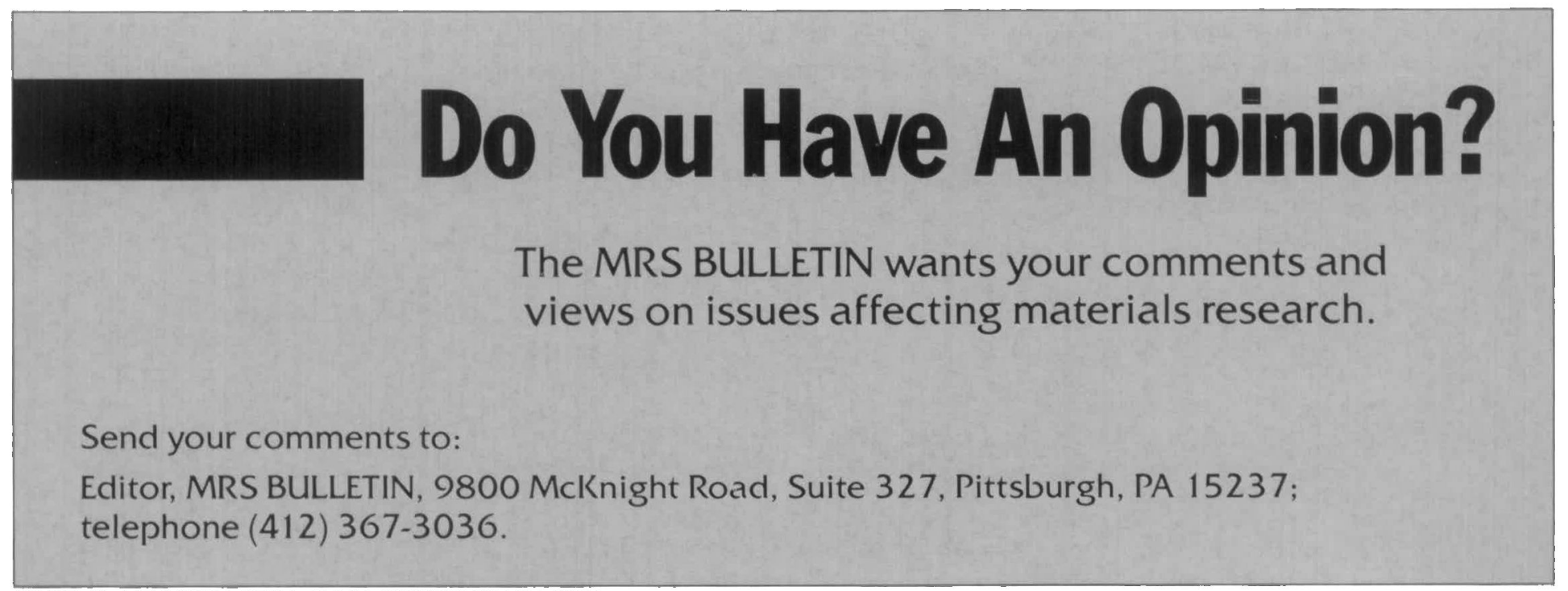




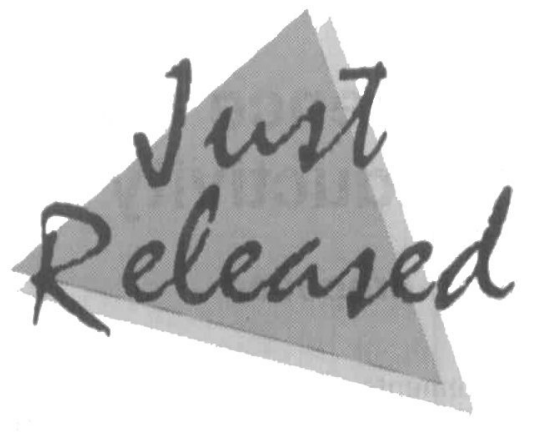

Videotape

The tape contains presentations by more than 70 scientists participating in the symposium from 10 countries. Edited to eliminate non-essential discussion, the videotape
The latest facts on the advanced superconducting ceramics that will revolutionize technology...

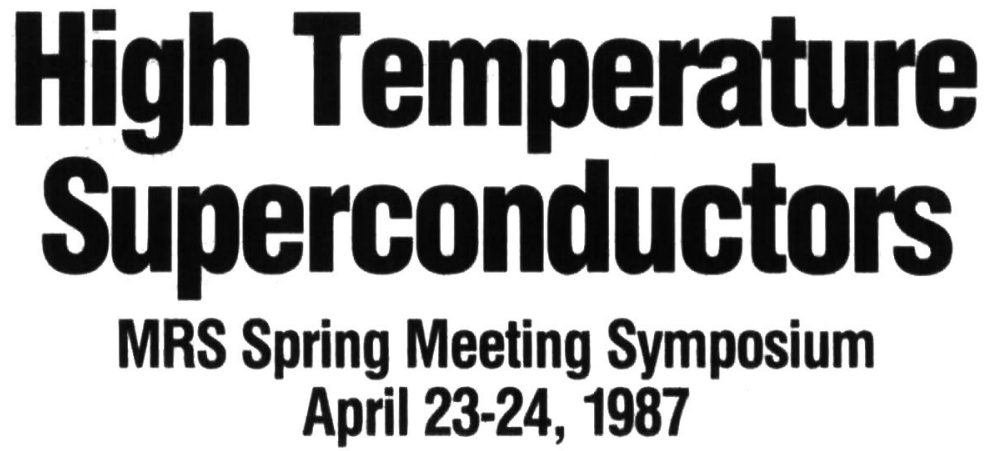

VHS

$\$ 165.00 /$ set u.s. MRs Members $\$ 180.00 /$ set Foreign MRS Members

$\$ 185.00 /$ set u.s. Nonmembers
$\$ 200.00 /$ set Foreign Nonmembers

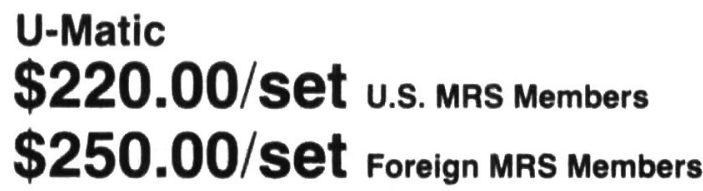

$\$ 260.00 /$ set u.s. Nonmembers $\$ 295.00 /$ set Foreign Nonmembers

Price includes UPS 2-day service in the U.S. and air mail service outside the U.S.

\section{Extended Abstracts Edited by D.U. Gubser and M. Schluter}

Printed complement to the seven-hour videotape of the MRS symposium includes extended abstracts of 68 presentations, each about three pages long and complete with illustrations and references. Presentations by some of the Contents include: runs approximately seven hours, showing all pertinent viewgraphs, as well as highlights of an international press conference conducted at the conclusion of the symposium.
A High $T_{c}$ superconductivity in layered perovskite-type oxides
$\Delta$ Mechanisms of high $T_{c}$ superconductivity in low dimensional materials
$\Delta$ Electronic structure of pure and doped orthorhombic $\mathrm{La}_{2} \mathrm{CuO}_{4}$
$\Delta$ Preparation of $\mathrm{YBa}_{2} \mathrm{Cu}_{3} \mathrm{O}_{7}$ and related compounds
A Energy gaps and thermodynamic fluctuations in high $\mathrm{T}_{\mathrm{c}}$ superconducting $\mathrm{Cu}$ oxides
$\Delta$ Reverse AC Josephson experiments in Y-Ba-Cu-O at $240 \mathrm{~K}$
A The 123 structure - its identification, isolation and universality
A Electron tunneling measurements in $\mathrm{LaSrCuO}$ and $\mathrm{YBaCuO}$
A Superconductivity in $\mathrm{Ba}_{2} \mathrm{Ln}$ (LANTHANOIDS $\mathrm{Cu}_{3}$ ) 9-x compounds
$\Delta$ Status report on the Berkeley research on high $T_{c}$ superconductors
$\Delta$ Thin films and SQUIDs made from $\mathrm{YBa}_{2} \mathrm{Cu}_{3} \mathrm{O}_{\mathrm{y}}$

Ordering Information

Extended Abstract, Volume EA-11, 277 pages, laminated paperbound, author index

\section{$\$ 10.00$ \\ Mrs Meneress \\ U.S. Nonmembers and Foreign}

Price includes shipping by fourth class book rate

Prepayment required. Make checks payable in U.S. dollars to: Materials Research Society. MasterCard, VISA, Diners Club accepted. Order from: Publications Department, Materials Research Society, 9800 McKnight Road, Suite 327, Pittsburgh, PA 15237; telephone (412) 367-3012. 